Archived version from NCDOCKS Institutional Repository http://libres.uncg.edu/ir/asu/

McCaughey, Martha. (2006) McCaughey, Martha. "Can Unscrewed be Unskewed? Television Coverage of the Internet," in First Monday 11:10 The version of record is available open access from the publisher at: http://firstmonday.org/issues/issue11 10/mccaughey/index.html or http://dx.doi.org/10.5210/fm.v11i10.1406 (October 2006). [ISSN: 1396-0458]

\title{
Can Unscrewed Be Unskewed? Television Coverage of the Internet
}

\author{
Martha McCaughey
}

\begin{abstract}
This paper documents one way the Internet is presented to the public by analyzing a late-night TV talk show about the Internet called Unscrewed on the TechTV cable network. I gained the opportunity to study Unscrewed, and attempt to influence its focus, when I was invited to appear as a guest on their show after having e-mailed them a criticism of their sexist coverage of the Internet - specifically their positioning of women as pretty objects to be ogled online rather than as creative participants in online culture and as authors of a diversity of Web sites. Though I liked the program's potential to challenge some aspects of an increasingly market-driven Internet, I was unable to unskew the sexist focus of Unscrewed precisely because market forces demanded the show remain male-centered.
\end{abstract}

\section{Introduction}

I accidentally got extended cable. I did not even have television at my old house, but I relocated to Boone, North Carolina and didn't know anyone. The cable guy said he couldn't set up the lines to give me just basic cable and tried to persuade me to buy the more expensive package of channels (except he didn't do it in that order). Since I only wanted the basic package, I ended up with all the extra channels, including TechTV, for free. Surprised that a new show, Unscrewed, featured the Internet, I eagerly began to watch. Only moments later I was outraged by the sexist way the show presented the Internet to the public. This paper tells the story of how I ended up a guest on the show - to critique it - and reveals the unsuccessful attempt of this feminist Internet studies scholar to unskew Unscrewed. 
Unscrewed was a new, hip, daily, late-night TV talk show about the Internet on the TechTV cable network, which aired in 2003, 2004, and 2005. Unscrewed humorously billed itself as "the shiny gold medallion atop the hairy chest of the tech world" and invited viewers to "take a walk on the wild side of tech pop culture." Unscrewed was an unrestrained romp through the seedy underbelly of the Internet, featuring individuals who have Web sites on alien visitations and on poop, online cartoons of singing kittens, online videos of motorcycle crashes, and silly quizzes such as "If you were an animal in bed, which one would you be?" Hosted by Martin Sargent, Unscrewed, if you never saw it, could be thought of as part The Man Show and part David Letterman only with a 29 year-old host with a computer at his desk and a cute female co-host by his side. Unscrewed guests were decidedly unfamous, unless you're really into Internet porn or alien-abduction Web sites. A noteworthy example of the seedy side of the Internet has been the phenomenon of women who run their own pornographic Web sites. In featuring one "girl gone wired" at the end of each show, Unscrewed came to represent the heterosexual male id unleashed.

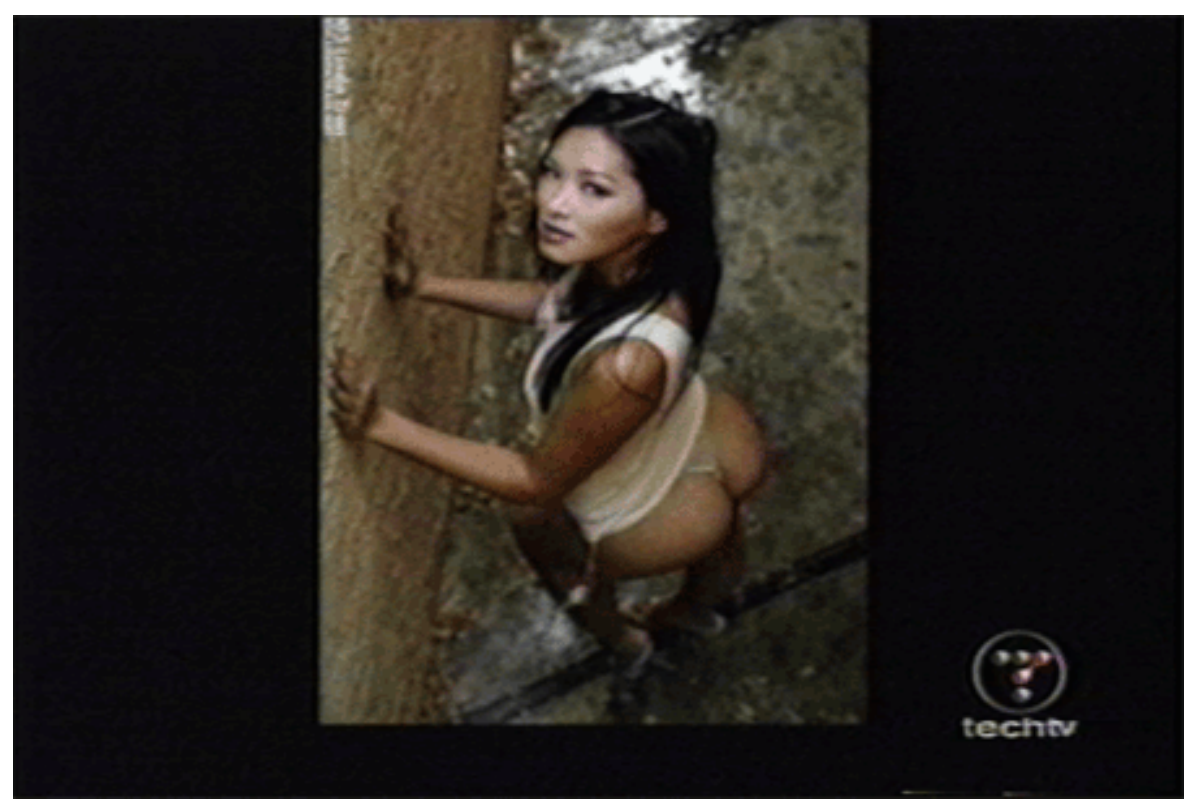

Figure 1: "Girls Gone Wired" from Unscrewed.

Being a show about Internet culture on the TechTV network, Unscrewed viewers were also encouraged to visit the Unscrewed Web site (one page among many TechTV show Web sites), which provided the links to the various and sundry Web sites covered on the show, allowing viewers to explore these sites further — and allowing the show to generate revenue by being the link through which viewers got to for-pay porn sites. The Web site also featured fans' chat rooms and silly commentaries about the Internet, games (e.g., The Unscrewed Drinking Game), and advertisements (including ads for the other shows aired on TechTV). 


\section{Unearthing Unscrewed}

I gained the opportunity to explore Unscrewed, and to attempt to influence its focus, after I had e-mailed the show a critique of their sexist coverage of the Internet - specifically their positioning of women as pretty objects to be ogled online rather than as creative participants in online culture and as creators of a multitude of Web sites beyond the pornographic. My critique of Unscrewed was that it positioned women as only the objects of the male gaze and not as creators of Web culture. The nightly segment called "Girls Gone Wired" was the perfect example of that. And, it was bogus for its soft-core style, featuring women in typical poses - reclining on beds, under waterfalls, standing with two fingers in their underpants. As feminist scholar Laura Kipnis (1992) argued years ago, the soft-core style of print porn (think Playboy) is more offensive than hard-core precisely because soft-core porn removes all sexual agency from the airbrushed, still-innocent women.

I wrote in, on a lark, with a snappy version of this critique, matching the tone of the show itself, expecting my e-mail to go unanswered. My message said:

Dear Martin and faithful staff of Unscrewed,

I am watching your show but I've got to say, like, what up with the malecentered techno coverage? I mean, we women are also technophiles and so it's pretty lame of you guys to have curvaceous female window dressing in your show, as opposed to actual Web sites that might interest women viewers ... . I mean, Girls Gone Wired? Hello. At least you could feature some sites in which men are like this ... if in fact you feel your show must cater to the lowest common erotic denominator ... .

(and PS: don't dismiss this suggestion as the rant of a woman who just can't get any).

Yours truly, Martha McCaughey 
Surprisingly, the Unscrewed booking agent called me after receiving my e-mail asking me to fly to their San Francisco studio and appear as a guest on the show. I did so, partly to study this first-ever television show about the Internet and partly because I (naively) believed the production team's claims that they really did want to make the show "smarter and better." Their wanting me on the show, they explained, came at a time when they were trying to improve the show. They were also surprised that a "real" women's studies professor would even watch Unscrewed; after all, I hardly fit their 18-35 year-old male demographic. Even my unflattering e-mail flattered Unscrewed. They also checked out my photo online and let me know that their decision was not unrelated to their assessment that I was camera-friendly.

The show's booking agent and segment producer allowed me to have input into the way my segment on the show would play out. I wanted to be sure a humorous critique of "Girls Gone Wired" was part of the segment. They agreed to my suggestion that we turn the tables and satirize "Girls Gone Wired" with "Guys Gone Wired," including Martin Sargent, the show's host, being posed in the very same positions that women are usually in, complete with the camera's usual lingering over the bodies and a backdrop of porno music.

Through my participant observation and conversations with the show's executive producer, booking agent, host, and co-host, I discovered that Unscrewed's male-centered message about the Internet was far smarter than I'd first assumed; I also realized that it was intentional in ways I hadn't understood, and unintentional in ways I'd assumed were intentional. Indeed, after my observations and continued discussions with the production team, I learned that the people behind Unscrewed were neither as unintelligent nor as unfeminist as I'd originally suspected.

The booking agent told me that the show's co-host, Laura Swisher, would love to have more opportunities to speak on the show beyond the pretty-girl sidekick kind of way she currently did. When I met the co-host, I learned that she had been a stand-up comedian and was somewhat critical of her limited role on the show (though was glad to have a job with a steady paycheck). She told me she found it perplexing that Unscrewed's young male audience members would enjoy the same old jokes about women's breasts.

From talking to the show's host, I learned that Unscrewed's coverage of women who run their own porn sites was intended to be an odd feature on just one show. However, they discovered through market research that their test audience liked the "Girls Gone Wired" segment most of all. And so to please their $18-35$ year old male demographic they made "Girls Gone Wired" a nightly feature of the show.

The host and co-host both told me they thought it odd that their audience found this segment so interesting, and clearly considered men sitting at their computers surfing porn rather pathetic. On the show they regularly made fun of the audience's interests. For example, on one episode of Unscrewed, the host introduced the featured "Girl Gone Wired" by saying, "For $\$ 18.95$ a month you can see Sondra naked, or you could feed a small village in Uganda. But you'll probably buy a subscription to her site, you selfish perv." On another episode the co-host introduced the featured "Girl Gone Wired" with this tongue-in-cheek statement: "Tonight's Girl Gone Wired is a U.N. translator. Just kidding. She's a fetish model." 
On one episode Laura Swisher did a wonderful parody in response to fans' asking her to be a Girl Gone Wired. Acting as though she'd decided to indulge the fans, the co-host described her decision to pose in her intimate space around her house. Viewers were then treated to photos of Laura posing unseriously and decidedly unseductively: in the morning drinking coffee, blearyeyed; in her bathroom flossing her teeth; and wearing a thick terrycloth bathrobe with a Q-tip stuck in her ear.

The very first spoof on "Girls Gone Wired" involved the host's reading of Moby Dick while showing the images of the scantily clad woman's Web pics. When I spoke with him, Martin explained that he had considered the segment so silly that reading aloud from his favorite novel was the only way to humor himself. He also meant to mock the men who weren't interested in literature in the face of a scantily clad model. While fans of Unscrewed enjoyed the way Martin made fun of his guests while they didn't even know it, apparently fans failed to realize that Martin was making fun of them, too.

But despite the occasional satirical gestures, Unscrewed's coverage of the Internet would remain male-centered, and downright sexist, precisely because of the way in which the show was driven by the need to secure dollars from advertisers. I had naively figured - and attempted to argue with the show's executive producer - that making the show appeal to both men and women would only increase their number of viewers and the show's overall popularity. I assumed that the producer just didn't realize that women, too, had a relationship with the Internet. I didn't understand, until he explained, that in the television industry a network more effectively pitches to advertisers when they can say, "we have the specific market you're looking for: 18-35 year-old men." Another television-industry executive explained that the 18-45 yearold male demographic is the hardest to reach on TV; adult men under 40 watch the least TV (as compared to retired men or male children). Advertisers are willing to invest substantially more money when they are assured that their advertisements will reach a strictly male population.

Thus TechTV did not want their demographic to change. They were happy the show presented a one-sided view of the Internet. The producer was even open to creating a show for women about the Internet. But he would not portray the Internet from a gender-inclusive lens because doing so would have made bad business sense. Unscrewed ultimately had no material incentive to interest women and continued to make a conscious effort to focus on Web sites that would interest young men. Indeed, while billing itself more broadly as a show about the wild side of tech pop culture, Unscrewed would really end up a Man Show about the Internet.

In his chapter on corporate media conglomerates on the Web, Joshua Gamson (2003) argues that capitalist interests increasingly shape what we see on the Internet, even when the Web sites look like or were originally sites of community and empowerment for marginalized groups. The Internet increasingly follows the market-driven principles of other communication media, and in the case of Unscrewed was represented in a skewed way precisely because it was represented on a TV show which itself follows market-driven principles. Unfortunately, then, Unscrewed was not improvable.

My segment turned out well enough anyway. It began with a few introductory jokes about my being a women's studies professor. For example, the host began by saying, looking at his cue 
card, "Up next, Unscrewed scores with a women's studies professor. That's not right, that's Unscrewed gets scored by a women's studies professor."

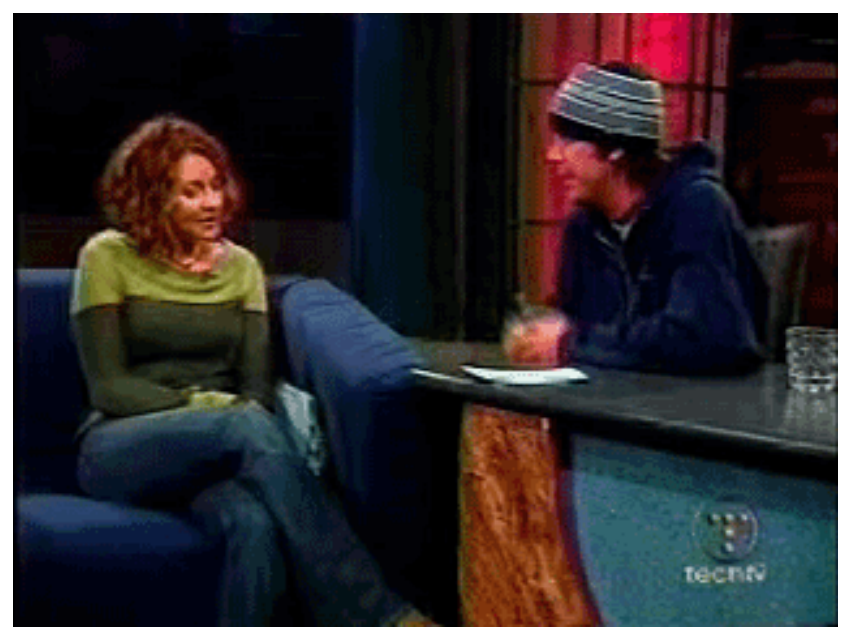

Figure 2: Author's appearance on Unscrewed.

Later in the segment, as the Internet researcher l'd "revealed" that l'd discovered that Martin was a Metrosexual (a straight man who takes an unusual interest in his appearance and physical pampering) - as a vehicle to show the "Photoshopped" images of the host looking like a sex object. Several shots of "Wind-kissed Martin Sargent with gorgeous flowing tresses" and "Martin Sargent luxuriates in 900 thread-count Egyptian cotton sheets" were displayed.

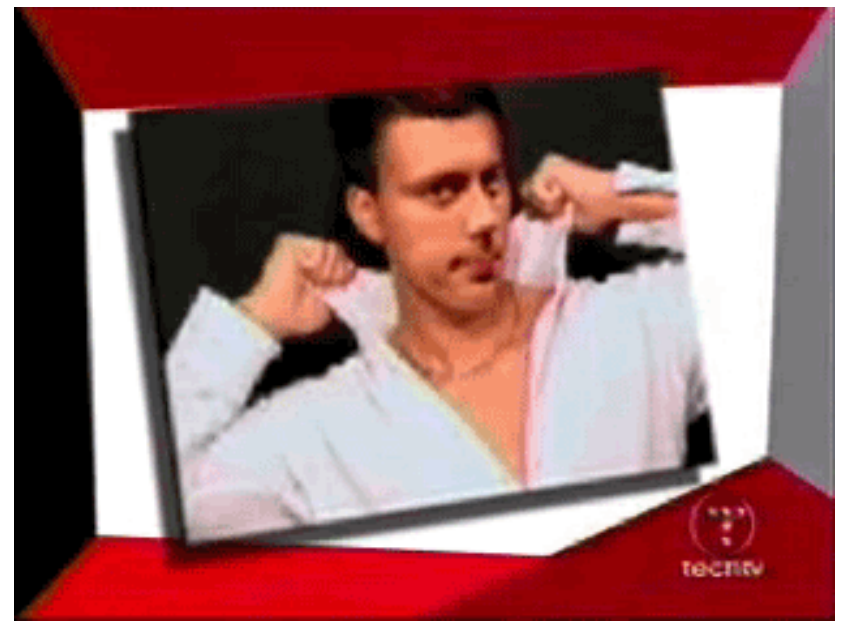

Figure 3: One of the images of Unscrewed's host as a "metrosexual." 
Co-host Laura Swisher orchestrated the final segment, following mine, while I remained on the set of the show. Just as Martin conceded that l'd had my fun with him, he went on to declare that despite what I said they were moving on to yet another Girl Gone Wired, at which point Laura interrupted with "No we're not" and introduced a segment she called "Guys Gone Wired." She then featured a male model from his Web site. However, it should be noted that the male model she chose was not running a porn site but simply had some standard modeling shots on his site. The man was not nude and he was always looking directly at the camera. The music from "Girls Gone Wired" ran as the camera panned the images of the male model, but Laura's lampooning commentary positioned herself as a fan of the model with whom she had a kind of imagined relationship born of arrogant imperceptiveness. (For example, she described stalking him and knowing he'd eventually become her boyfriend.).

Checking the Unscrewed Web site after this episode, I could see that male fans hated to "see guys," the majority insisting that "Guys Gone Wired" should not exist, and that men should not have to shave, or do other things to improve their appearance. They simultaneously insisted that Unscrewed should continue to show "Girls Gone Wired," the female equivalent of metrosexual men on display. Despite the offense fans took at seeing a man depicted as a sex object, some admitted to being sympathetic to the co-host, and enjoyed seeing her "get even with" the male host with the segment "Guys Gone Wired." It was clear that the market researchers were right about the popularity among Unscrewed fans of "Girls Gone Wired."

A reason for the popularity of "Girls Gone Wired" occurred to me while I sat in the audience for the show's taping. I sat among an audience with maybe 25 chairs, filled with almost all young men under the age of 30 , to watch the taping of the show prior to the one on which I appeared. It was clear to me that the men were huge fans of Martin, the show's host. They hung on his every word. They laughed at everything he said and did. They noticed his "cool boots, man" before the show began taping. On the show Martin acted as though he'd found these sites of naked women, silly quizzes, and cool digital videos; but of course the various segment producers found much of the material he'd present. It's no wonder male fans of Unscrewed loved Martin Sargent: he's the cool nerd they want to be, a techie geek with social skills, quick wit, good looks, and charm.

But of course Martin Sargent is not a techie geek, as indicated by his Cornell University humanities background and his somewhat proud confession to me after the show that he didn't even have a computer until two months prior to my meeting him - almost a year into the show. Indeed, Martin fell into this role sideways, after traveling around the country and settling in San Francisco to be a writer, during the dot-com boom when the only writer job he could get was with a computer magazine. This led to his foray into another TechTV show, then to hosting his own show about the Internet. So, as you might have guessed, it's much easier to be a cool guy with social skills pretending to be a computer nerd than the other way around.

Male fans were so enamored with Martin that the only thing keeping them comfortably heterosexual was the opportunity to hoot and holler over women getting naked, something they no doubt thought their idol Martin Sargent celebrated as well. That he's far more educated and mature than they are is something about which they seemed completely unaware. And so it was 
that "Girls Gone Wired" served as the heterosexual alibi for the young men who really adored Martin.

While I was relieved that the people hosting and producing Unscrewed weren't as unintelligent and un-feminist as I'd suspected - indeed, I found them smart, funny, and progressive — I felt disappointed learning that market forces ruled Unscrewed's contents. And, I became even more troubled as I realized that Unscrewed staffers didn't seem to "get" the feminist intervention I was attempting to make.

Recall that l'd suggested a "Guy Gone Wired" segment using images of the host himself, "Photoshopped" onto pornographic images of young, smooth, reclining male bodies. The images staffers ended up "Photoshopping" for the Martin-as-metrosexual portion of my segment were not airbrushed pretty boys posed in vulnerable, reclining, or butt-in-the-air positions. Indeed, the staff initially "Photoshopped" Martin's head onto advertisements featuring male models, who are standing straight up, wearing pants (and usually shirts as well), and looking straight at the camera. On the day of the taping, I begged staffers to do at least one of Martin lying in bed.

Thankfully, they did it, by going to a gay porn site and morphing Martin's head onto the body of a man posing in bed with a sheet over his erection.

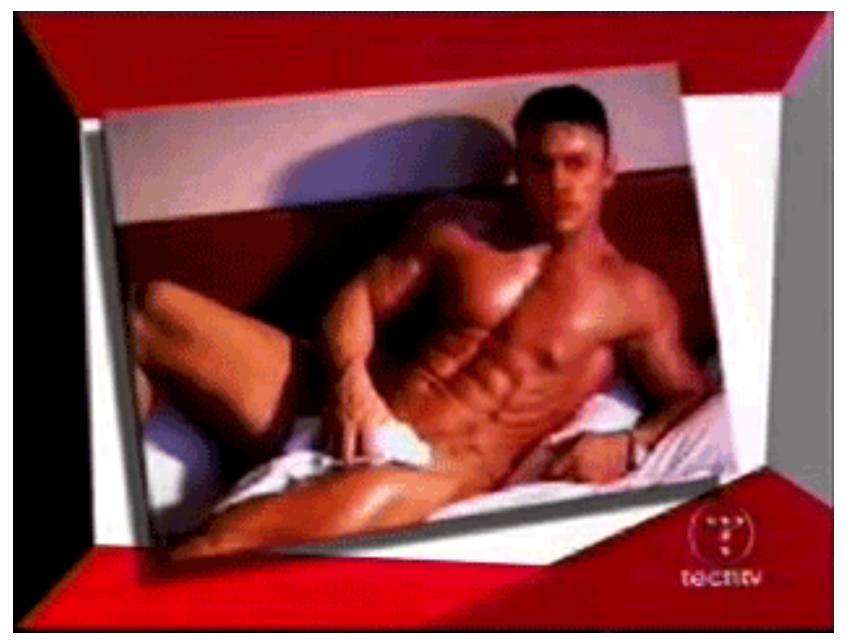

Figure 4: The only image of the show's host that came close to a real parody of "Girls Gone Wired."

There were still no photos of a man reclining vulnerably, sticking his butt out, wearing sexy underwear, standing under a waterfall, or spreading his legs - the standard poses of women on the "Girls Gone Wired" porn sites. The sexist expectation to see women's bodies displayed in specific positions, and the accompanying inability to imagine a male body on display that same 
way, allow people to think a male model posing for a camera in a straight-on shot is the equivalent.

Unfortunately, for Unscrewed an unforgiving satire of "Girls Gone Wired" was unimaginable.

\section{Conclusion}

While I came to realize that Unscrewed would never be "unskewed," I also believe that Unscrewed was nevertheless an important, and cutting edge, representation of the Internet. For example, other than women's porn sites, it featured non-commercial sites on the Internet (albeit not the political ones). And, perhaps most significantly, the show pushed the envelope of fair use by using other sites constantly, and not just for critique. For example, during my segment the point of which was to satirize "Girls Gone Wired" - show staffers had taken images from porn sites and advertisements of men from the Web. The show routinely employed sites not just for discussion but for manipulation. In an era of wars over copyright, intellectual property, and free speech online, Unscrewed staked a claim for fair use and against many of the laws that regulate individual use of the Internet.

Unscrewed also pushed the envelope with its occasional segment called "Dark Tipper," in which a tech-savvy and handsome young man shared tips on what viewers could do with specific equipment to accomplish something the corporation selling the product never intended — from blowing up a hard drive to copying DVDs to installing lenses with $\mathrm{X}$-ray vision on a digital video camera. With a big wink the dark tipper would say something like, "Oh, and people, this is illegal and you could be violating the Digital Millennial Copyright Act by doing this, so don't do this."

The show did not get challenged legally, but had it remained on the air and become more popular, I expect it eventually would have been. By catering to market forces, Unscrewed was an underachiever, yet in the era of copyright, intellectual property, and free speech online, clearly the underdog I'll root for, even if I have to put up with four minutes of unimaginative sites with underfed women modeling undergarments.

After TechTV was bought by the Comcast Network, Unscrewed was dropped in favor of shows supporting Comcast's main industry, video games. The former TechTV show reviewing video games, X Play, remains on the air, on the G4 Network. It's worth noting that fans of Unscrewed on its message board lamented the takeover of TechTV by Comcast. One female fan said:

They plan to gradually overturn all programming and make it their teenage-boy-gamer-centric schedule. Apparently they don't believe that any show worth viewing 
by females, or anyone over 25 , fits

their plans. We can say goodbye to

all of the real technology shows, the

news, and probably to Unscrewed as

well.

Another fan said:

\begin{abstract}
Comcast has one interesting partial
owner - Microsoft. In the early days

of @Home (1997), Bill Gates gave

Brian Roberts one billion dollars

toward Comcast Online. Microsoft

now owns between $7 \%$ and $11 \%$ of

Comcast, depending on what reports

you read. And Comcast has an

interest in interactive TV, including

gaming. All this does is give them an

easier road into the Other MSOs

markets. Now my question is, will

anyone have the balls to step up and

start a "new" TechTV for those of us

who preferred it in its best form? With

actual discussion of Linux? With

critical analysis of Comcast and

Microsoft? And why hasn't Apple

sued them over use of the G4 name?

I'm incredibly disheartened and bitter

over this.
\end{abstract}

Unscrewed is now history and Comcast's G4 channel promotes computer games. But Unscrewed may well appear soon in a new form, on some other network. If it does, fans can only hope that the show does not sacrifice its tech-savvy qualities in exchange for added lewd or sophomoric content.

\title{
Acknowledgements
}

Thanks go to Frances Montell, who coached, watched, and analyzed the author's entire Unscrewed experience. 


\section{References}

Joshua Gamson, 2003. "Gay Media, Inc.: Media Structures, the New Gay Conglomerates, and Collective Sexual Identities," In: Martha McCaughey and Michael D. Ayers (editors). Cyberactivism: Online Activism in Theory and Practice. New York: Routledge, pp. 255-279.

Laura Kipnis, 1992. "(Male) Desire and (Female) Disgust: Reading Hustler," In: Lawrence Grossberg, Cary Nelson, and Paula A. Treichler (editors). Cultural Studies. London: Routledge, pp. 373-391. 